\title{
STRESS AND STRAIN OF AGING INNOVATORS IN THE PRODUCT DEVELOPMENT PROCESS
}

\author{
Kerstin Nawroth \\ Institute of Ergonomics, University of Technology Hamburg-Harburg \\ Hamburg, Germany
}

Workforces in industrialized countries in general are becoming older because the babyboom generation is reaching an advanced age and the percentage of young employees is constantly decreasing. The demographic change going along with this is frequently seen as a cause for the stagnation of innovations. For the companies the question arises, as or whether older and younger employees in the Research and Development (R\&D) sector differ concerning innovation level and activity in individual stages of the product development process.

While gerontologists often emphasize increasing abilities of older employees (e.g., reliability and specific knowledge), managers emphasize decreasing abilities (e.g., physical capacity and learning abilities). Therefor, case studies in 30 companies of various industries and sizes in Germany looked into how activity-related support structures of older and younger employees in $\mathrm{R} \& \mathrm{D}$ are arranged. The objective was to state the cooperating of younger and older innovators, that can lead to an optimized knowledge management.

In the companies, resources and creativity were looked at very differently. There were some companies in innovative sectors with a large number of older employees as well as others, that had reduced their older staff significantly. Companies aiming at continuity, for which they need the experience of older employees and mastering of complex processes, tend towards R\&D-teams of mixed ages. However, the surveys show that the assumption, that innovation is only possible with young people and that an aging workforce is a major problem, is not quite so tenable.
The innovators' fields of activity depend on the company's strategy, they shift particularly due to operational restructuring. Information is frequently missing, which leads to different effects regarding the orientation of older and younger innovators. Figure 1 shows barriers for innovation, differently seen by younger and older innovators (aged 45 and over).

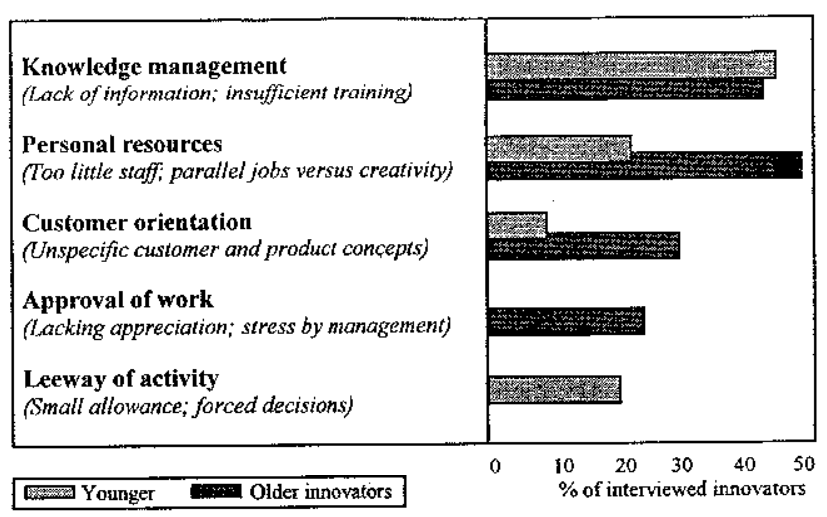

Figure 1: Innovators views on barriers for innovation

Older employees have a good knowledge of the company's internal resources. Due to their special positions they are connected with their companies in many different ways. Also they are equipped with sufficient influence and power in the company, in order to start up investment and growth strategies.

There is a concrete organization potential concerning age-appropriated employment of innovators. Aging has to be looked at, not only as a personal change of ability, but also as an integrative change of the ability of a company's system. Important elements are appropriate personnel development and innovative training which motivates and qualifies innovators for challenging new tasks. 